\title{
Esporte na escolav e esporte de rendimento
}

Valter Bracht*

\author{
Como lidar com um fenômeno \\ tão poderoso como o esporte \\ sem sucumbir a ele? \\ (Ricardo Lucena, 1999)
}

\section{INTRODUÇÃO}

O tema esporte de rendimento na escola foi avaliado pela editoria da revista Movimento como controverso e como tal eleito para ser discutido na seção da revista destinada exatamente ao debate de temas de caráter polêmico. Dentro desta perspectiva fui convidado para expressar minha opinião e/ou posição a respeito.

Inicialmente fiquei me perguntando: o tema é realmente polêmico? ou seja, mobiliza a comunidade da área num debate onde posições distintas disputam a hegemonia?

Efetivamente o esporte de rendimento ${ }^{1}$ já esteve sim no centro das dicussões pedagógicas na Educação Física (EF). Algumas razões para tanto foram ou são: a) o esporte (de rendimento) tornou-se a expressão hegemônica da cultura de movimento no mundo moderno; $b$ ) uma das bases da legitimação social do sistema esportivo era sua alegada contribuição para a educação e a saúde; c) o esporte é/era o conteúdo dominante no ensino da EF; d) o sistema esportivo via na escola uma instância contribuidora importante para o seu desenvolvimento, uma de suas "bases"; e) com a sociologia crítica do esporte (e da educação) surgem dúvidas quanto ao valor educativo do esporte.

Embora o tema nunca tenha saído efetivamente de pauta, ele, enquanto objeto de polêmica, parece viver um "renascimento". O que estaria fazendo com que este tema adquirisse novamente um caráter polêmico, ou seja, fosse capaz de mobilizar a comunidade para um debate?

É a constatação de que o tema não se esgotou? Que teriam permanecido questões fundamentais a serem discutidas? Em suma, seriam razões "internas" ao debate? Sim e não! Assim como na década de 80 o esporte vai tor- nar-se objeto de severa crítica a partir de desdobramentos no plano social mais geral, também agora parece que o debate é reativado por alguns desdobramentos sócio-políticos. Quais seriam as circunstâncias sociais que estariam mobilizando a comunidade para este debate neste momento?

A princípio parece haver aqui um paradoxo; o debate aparenta estar na contramão. Senão vejamos: a $\mathrm{EF}$ (escolar) passa por um momento em que sua existência encontra-se ameaçada e isto na medida em que foi abandonada pelo projeto neo-liberal de educação e pelo próprio sistema esportivo que dela pode prescindir para o seu desenvolvimento, pois as escolinhas esportivas substituem com "vantagens" a EF. Assim, parece-nos que o reascendimento da polêmica é suscitada muito mais pelas ações ligadas à política para o setor dos últimos dois governos federais através do INDESP, que entendeu que 
uma das formas de dar urna contribuição para o engrandecimento esportivo do país (leia-se: conquistas esportivas, medalhas olímpicas, etc.), seria investir na investigação no âmbito das Ciências do Esporte e com isso vem financiando os Centros de Excelência, que entre outras coisas, desenvolvem projetos no âmbito da detecção de talentos esportivos. Para que este tipo de investigação seja legitimada em centros de investigação ligados a Escolas de Educação Física, é preciso "recuperar a dignidade pedagógica" ${ }^{2}$ do esporte de rendimento, caso contrário, o que justificaria o esforço financeiro e de pessoal, envolvendo recursos públicos, para o seu desenvolvimento? Embora o esporte de alto rendimento (que é esporte espetáculo) tenha aprofundado sua mercadorização — sendo hoje, mais que outrora, regido pelas leis de mercado - o Estado brasileiro, que orienta-se em princípios conhecidos como neo-liberais, ainda se sente responsável por apoiar com formação de mão-deobra especializada, com conhecimento científico, sem falar nos subsídios diretos, o desenvolvimento deste sistema. Assim, busca legitimidade para suas ações no campo. Embora tenha amplo apoio social nesta iniciativa, pela ampla unanimidade da qual desfruta o esporte enquanto bem cultural, para o que a imprensa colabora e muito, no âmbito acadêmico parece haver algum tipo de resistência ... geradora de polêmica.

\section{RETOMANDO O DEBATE}

Mas, nosso objeto não é propriamente o esporte de rendimento e sim, a relação entre o esporte de rendimento e a $E F$, entendida esta enquanto uma prática pedagógica presente na instituição educacional.

Não vou recuperar aqui toda a crítica ${ }^{3}$ feita ao esporte de rendimento enquanto elemento da EF, revisitando os argumentos prós e contras. Vou limitar-me a elencar e discutir os pontos que considero tenham sido objeto de equívocos e mal-entendidos no interior do debate. Portanto, serei seletivo, pressupondo um certo envolvimento com o tema por parte dos leitores. Estou usando como estratégia também, a anexação de pequenos textos ilustrativos (para-textos) que podem ser lidos também isoladamente.

Parece-me que numa perspectiva bem genérica, o esporte de rendimento enquanto elemento da EF foi colocado sob suspeita a partir das teorias da reprodução, desenvolvidas no âmbito da sociologia da educação e que enfatizavam o papel conservador do sistema educacional nas sociedades capitalistas. A EF ao fazer do esporte de rendimento seu objeto de ensino e mesmo abrindo o espaço escolar para o desenvolvimento desta forma de realizar o esporte, acabava por fomentar um tipo de educação que colaborava para que os indivíduos introjetassem valores, normas de comportamento conforme e não questionadores do sistema societal. E isto porque o esporte de rendimento traz na sua estrutura interna, os mesmos elementos que estruturam também as relações sociais de nossa sociedade: forte orientação no rendimento e na competição, seletividade via concorrência, igualdade formal perante as leis ou regras, etc. Ressaltese que colaboraram para o desenvolvimento de uma visão crítica do esporte também a sociologia crítica do esporte que ganha enorme impulso nas décadas de 70 e 80 (cf. Bracht, 1997). Isto tudo, levou as pedagogías críticas da EF, nascentes naquele momento (década de 80), a repensar a relação que a EF deveria ter com o esporte (de rendimento).

Importante dizer que o esporte, enquanto fenômeno cultural, foi assimilado pela $\mathrm{EF}$, inicialmente, sem que isto modificasse a visão hegemônica de sua (da EF) função social (desenvolvimento da aptidão física e do "caráter"), mas, paulatinamente, o esporte se impõe à EF, ou seja, instrumentaliza a EF para o atingimento de objetivos que são definidos e próprios do sistema esportivo. Este processo não vai ser acompanhado de uma reação crítica da $\mathrm{EF}$, muito ao contrário, ele foi saudado como elemento de valorização da $\mathrm{EF}$, que passa a ser sinônimo do esporte na escola. A reação se dá tardiamente, como já observado, na década de $80 .{ }^{4}$ 
Quando então, na EF, sob a influência das teorias críticas da educação e da sociologia crítica do esporte se faz a crítica ao esporte, principalmente ao de rendimento, no sentido do seu papel educativo no âmbito escolar, acabam por se instalar uma série de mal-entendidos e equívocos, que, infelizmente ainda grassam em nosso meio (alguns, para meu quase desespero, já se cristalizaram). Ao tratá-los espero poder deixar clara minha posição e colaborar para uma melhor compreensão do tema.

\section{EQUÍVOCO/MAL ENTENDIDO 1}

Quem critica o esporte é contra o esporte. Criticar o esporte ficou sendo entendido como uma manifestação de alguém que é contrário ao esporte no sentido lato. Com isso criou-se uma visão maniqueísta: ou se é a favor, ou se é contra o esporte. A EF foi dividida por este raciocínio tosco, entre aqueles que são contra, de um lado, e aqueles que são a favor do esporte, de outro.

Esta visão tosca trabalha com o pressuposto de que o esporte é algo a-histórico. Com efeito, é comum ouvir-se falar neste contexto em "essência do esporte", em "natureza do esporte". Ora, o esporte é uma construção histórico-social humana em constante transformação e fruto de múltiplas determinações. Assim, críticas ao esporte só podem ser endereçadas ao seu

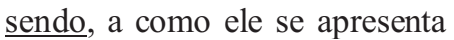
historicamente. E no caso da pedagogia crítica da EF com vistas a sua superação, o que significa, buscar colaborar para que este esporte assuma outras características, estas então, mais adequadas a uma outra (alternativa à hegemônica hoje) concepção de homem e sociedade.

A negação do esporte não vai no sentido de aboli-lo ou fazê-lo desaparecer ou então, negá-lo como conteúdo das aulas de EF. Ao contrário, se pretendemos modificá-lo é preciso exatamente o oposto, é preciso tratá-lo pedagógicamente. É claro que, quando se adota uma perspectiva pedagógica crítica, este "tratá-lo pedagógicamente" será diferente do trato pedagógico dado ao esporte a partir de uma perspectiva conservadora de educação.

\section{EQUÍVOCO/MAL ENTENDIDO 2}

Tratar criticamente $o$ esporte nas aulas de EF é ser contra a técnica esportiva. Portanto, os que não são críticos são tecnicistas. Por outro lado, aqueles que dizem tratar criticamente o esporte na EF negam a técnica, são contra o ensino das técnicas esportivas.

Quando um determinado bem é valorizado socialmente, busca-se aperfeiçoar os procedimentos para a sua efetivação (produção), ou seja investe-se no desenvolvimento de técnicas com este objetivo. O que é fundamental a perceber é que a técnica é (deve ser assim considerada) sempre meio para atingir fins. Estabelecer fins/objetivos (sentido) é que é um predicado humano, portanto a técnica deve ser sempre subordinada às finalidades humanas. Se variam as finalidades, os sentidos da prática esportiva, é conseqüente que variem também as técnicas, bem como seu valor relativo.

Tanto num jogo de tênis pela Taça Davis, quanto num jogo de frescobol numa praia qualquer, a técnica está presente (movimentos aprendidos para realizar fins). No entanto, o valor relativo da técnica empregada, o sentido e o resultado social do emprego das técnicas são muito diferentes nos dois casos. Portanto, o que a pedagogia crítica em EF propôs/propõe, não é a abolição do ensino de técnicas, ou seja, a abolição da aprendizagem de destrezas motoras esportivas. Propõe sim, o ensino de destrezas motoras esportivas dotadas de novos sentidos, subordinadas a novos objetivos/fins, a serem construídos junto com um novo sentido para o próprio esporte. ${ }^{5}$

No caso da lógica do sistema esportivo, o rendimento almejado é o máximo, não o possível ou o ótimo, considerando as possibilidades individuais e dos grupos. No sistema esportivo o próprio rendimento máximo tornou-se o objetivo a atingir. Desta forma, os meios (técni- 
cos) alcançam grande centralidade neste sistema. Há um enorme investimento no desenvolvimento técnico que permitirá o máximo de rendimento que permitirá, por sua vez, sobrepujar o adversário. Esta lógica aparece já no processo de iniciação esportiva, de forma muitas vezes inconsciente.

No esporte de rendimento as ações são julgadas pelo seu resultado final, a performance esportiva mensurada/valorizada em função do código binário da vitóriaderrota. Os meios empregados no treinamento, o próprio treinamento, tudo é medido pelo resultado final. A própria prática, o processo, a fruição do jogo não assumem importância significativa para o sistema.

$\mathrm{O}$ que se criticou e se critica então, é a subordinação inconsciente não à técnica enquanto tal, mas à finalidade a qual determinada técnica está a serviço.

Não é preciso repetir aqui o quanto as ciências naturais e suas irmãs ciências sociais e humanas que copiam seu modelo, foram engajadas com vistas ao objetivo de maximizar o rendimento: a fisiologia, a biomecânica, a aprendizagem motora, a psicologia, a sociologia, etc. Para atingir este objetivo, o de maximizar o rendimento, o grande modelo de corpo de atleta foi o do corpo-máquina (máquina maravilhosa), capaz de performances espetaculares.
Em função da centralidade do desenvolvimento técnico para os objetivos do sistema esportivo (esporte de rendimento), criou-se o jargão de que os professores de EF que defendem o esporte de rendimento seriam tecnicistas. A confusão aumentou quando, ao se discutir a literatura pedagógica e, com o seu auxílio, operar análises do que acontecia na $\mathrm{EF}$, começou-se a confundir o tecnicismo esportivo com o tecnicismo pedagógico, ou com a pedagogia tecnicista. Embora seus princípios epistemológicos sejam os mesmos, o que facilitou a incorporação da pedagogia tecnicista no ensino do esporte na escola, trata-se de duas coisas bastante distintas. Não se está adotando a pedagogia tecnicista simplesmente porque se ensina técnicas esportivas.

\section{EQUIVOCO/MAL-ENTENDIDO 3}

Já pode o leitor perceber que a separação entre os diferentes mal-entendidos é apenas formal-didático, porque eles estão entrelaçados. Assim, orgânicamente ligado ao anterior, outro equívoco é o de que a crítica da pedagogia crítica da EF era destina$d a$ ao rendimento enquanto tal, e que a este contrapunha, em posição diametralmente oposta, o lúdico. Nova contraposição maniqueísta ${ }^{6}$ : os do rendimento $x$ os do lúdico (os do formal $x$ os do informal; os do alto nível $x$ os do EPT, etc). Do lado do rendimento estariam todos os de- feitos: mecanização do homem, orientação pela razão instrumental, sacrificio, dor, manipulação, etc; do lado do lúdico todas as virtudes: prazer, espontaneidade, liberdade, verdadeira humanização. ${ }^{l}$ Me parece que há nesta posição uma idealização do lúdico, como espaço, dimensão do humano a-priori a ser preservado da colonização da razão (científica) e seus produtos. No esporte de rendimento haveria como que uma racionalização (pela razão técnico-instrumental) do jogo, do lúdico. Ora, o comportamento lúdico não existe na sua forma pura, ele está mais ou menos presente em uma série de práticas humanas, portanto, moldado culturalmente. A crítica é endereçada, na verdade, ao fato de que na nossa sociedade, todas as ações humanas tendem a ser guiadas pela razão técnico-instrumental. A crítica é à hegemonia da razão técnico-instrumental, que numa determinada perspectiva marxista, significa a coisificação de todas as relações sociais-humanas. Pareceme que a contraposição a esta tendência não deveria se fazer pela afirmação do seu contrário, o primado da sensibilidade, do acaso, do lúdico, por uma volta à uma unidade primordial (natureza/homem, mundo/homem) e sim, pela mediação, pelo reconhecimento da ambigüidade de nosso ser/estar (n)o mundo, pela superação qualitativa da razão instrumental e não pelo "retorno" ao sensível original.

Conseqüência paralela: 
como o rendimento está condicionado à capacidade física, acusa-se aqueles que defendem o esporte enquanto jogo, de negarem a aptidão física ou a atividade física enquanto promotora de saúde. Não se trata de negar os benefícios das práticas corporais para a saúde, embora isto precisasse ser mais relativizado do que querem alguns apologetas da atividade física como promoção de saúde. Trata-se apenas de não reduzir o sentido destas práticas a este objetivo e também, de não entender que a especificidade da EF (e sua função na escola) seria exatamente a promoção da saúde.

\section{EQUIVOCO/MAL ENTENDIDO 4}

Tratar criticamente do esporte na escola é abandonar o movimento em favor da reflexão.

Outro equívoco que se construiu foi o de que os críticos do esporte de rendimento enquanto conteúdo de ensino da $E F$, quereriam substituir o ensino das destrezas esportivas pelo discurso sociológico ou filosófico sobre o esporte, transformando as aulas de EF em aulas de sociologia/filosofia do esporte (de preferência desenvolvidas em sala de aula - aula teórica).

Não se trata de substituir o movimento pela reflexão, mas de fazer esta acompanhar aquele. Para isso, não é preciso ir para a sala de aula! Mas é preciso também, não reduzir a mudança apenas ao ato de acrescentar a reflexão à prática, e sim entender que a própria prática, a própria forma do movimentar-se esportivo precisa ser reconstruída. ${ }^{8}$

\section{CONSIDERAÇÕES FINAIS}

Minhas reflexões anteriores partem de um pressuposto que me parece óbvio, mas que talvez precise ser explicitado. No meu entender o esporte na escola, ou seja, o esporte enquanto atividade escolar só tem sentido se integrado ao projeto pedagógico desta escola. Como conseqüência é necessário analisar o quadro das concepções pedagógicas e fazer opções. É preciso analisar o tipo de educação possível a partir de cada uma das manifestações do esporte, integrando estas análises discursiva e praticamente na concepção pedagógica eleita. Assim, a realização de uma pedagogia crítica ${ }^{9}$ em EF está condicionada por aquilo que acontece na escola como um todo, e muito provavelmente apresentará os avanços e as contradições deste contexto. A mudança na EF está condicionada pela mudança da escola e esta pela da sociedade. Para um projeto político-pedagógico que não entende como problemático educar no sentido da integração ao sistema societal vigente, a maioria das críticas ao esporte de rendimento feitas pela pedagogia crítica, não fazem sentido.

Sabemos da sociologia do currículo que nem todos os saberes produzidos no contex- to cultural mais amplo adentram a escola, ou seja, são escolarizados para compor os currículos escolares. Dois aspectos neste processo nos interessam de perto: a) a escola seleciona, vale dizer, privilegia determinados saberes; b) escolariza os saberes, ou seja, eles passam por uma mediação didático-pedagógica (muitas vezes se fala em transposição didática). Questões importantes derivam destes dois pontos. A partir de quais critérios, saberes são considerados relevantes ou irrelevantes para merecerem a atenção da escola? Porque, por exemplo, o esporte deve ser um saber escolar ou compor as atividades da escola? Quais interesses, que grupos de pressão definem se o esporte fará ou não parte das atividades escolares? Ou ainda, na mediação didático-pedagógica do esporte, transformando-o em atividade escolar, por quais mudanças ele deve passar? ou ele deve aparecer na escola tal qual se apresenta no plano cultural mais geral?

Porque o esporte foi escolarizado? Sem poder me alongar neste ponto, diria que vários foram os interesses que pressionaram neste sentido, entre eles os interesses do próprio sistema esportivo com o objetivo de socializar consumidores e produzir futuros e potenciais atletas. Aliado do sistema esportivo, na maioria dos casos, foram os Estados, o poder público, que se colocou como tarefa intervir no sentido de que a nação, o estado ou o município fosse bem representado nas disputas es- 
portivas nos diferentes níveis. Para o sistema esportivo interessava que a escola, ao incorporar o esporte, o fizesse de maneira a desenvolvê-lo numa forma o mais próxima possível de como ele acontece no próprio sistema esportivo. Pedagogizar o esporte tornouse um problema para o sistema esportivo, porque coloca nesta prática elementos que acabam entrando em confronto com os principios, com a lógica que orienta as ações no âmbito do esporte.

Existe urna forma de prática esportiva onde o rendimento e a competição tenham um outro papel, um outro sentido, diverso daquele que possuem no âmbito do esporte de rendimento ou alta competição? Entendemos que sim. Portanto, o esporte tratado e privilegiado na escola pode ser aquele que atribui um significado menos central ao rendimento máximo e à competição, e procura permitir aos educandos vivenciar também formas de prática esportiva que privilegiem antes o rendimento possível e a cooperação. Mas, como sabemos da sociologia do currículo, esta escolha depende da correlação de forças entre os diferentes interesses sociais. Não é mera coincidência que a escola, principalmente a privada, "desiste" das aulas de EF e promove as escolinhas de esporte.

Para finalizar gostaria de fazer ainda duas observações:

a) Não desconheço as dificuldades de realizar uma prática pedagógica crítica em EF envolvendo o fenômeno cultural do esporte. Esta é uma possibilidade no entanto, que está sendo construída, portanto não é uma missão impossível. Existem várias experiências sendo realizadas por professores de diversas regiões do Brasil, que fizeram esta opção, que lutam com um quadro adverso é verdade, mas que não desistem porque acreditam nessa necessidade e neste projeto político-pedagógico.

b) Alerto para que não se interprete a tentativa de argumentação presente neste texto como uma defesa da idéia de que as opções éticopolíticas que todo professor de EF faz, quer queira quer não, consciente ou inconscientemente, que estas opções sejam de caráter técnico, ou seja, de que seria possível medir com um instrumento técnico e "objetivo" o valor (tamanho) dos argumentos prós e contras e então decidir a favor de uma posição. A construção destas posições, as tomadas de decisão neste campo (ético-político) é (são) um processo extremamente complexo que envolve dimensões racionais e não-racionais (estéticas), estruturais e conjunturais, e é exatamente neste fato que radica a necessidade da democracia, entendida como uma proposta de auto-referencialidade, ou seja, não existe um fundamento último onde poderíamos buscar um critério ineludível para nossas opções ou decisões.
Daí também a necessidade do debate para fortalecer o caráter público das decisões, para lhes fornecer qualidade.

\section{REFERÊNCIAS \\ BIBLIOGRÁFICAS}

BRACHT, V. Educação física no $1^{\circ}$ grau: conhecimento e especificidade. Revista Paulista de Educação Física. Sup. 2, 1996, p.23-8.

_. Sociologia crítica do espor te: uma introdução. Vitória: CEFD/UFES, 1997.

BROHM, J.-M. (org.). Deporte, cultura y represión. Barcelona: Ed. Gustavo Gili, 1978.

EICHBERG, H. Der Weg des Sports in die industrielle Zivilisation. Baden-Baden: Nomoa, 1979.

KUNZ, E. Transformação didático-pedagógica do esporte. Ijuí: UNIJUİ, 1994.

HARGREAVES, J. Sport, culture and ideology. London: Routledge \& Kegan Paul, 1982.

SAVIANI, D. Escola e democracia. São Paulo: Autores Associados/Cortez, 1983.

SILVA, T. T. da . Documentos de identidade; uma introdução às teorias do currículo. Belo Horizonte: Autêntica, 1999.

\section{Textos ilustrativos (para-textos)}

Santin, Silvino. Educação Física: da alegria do lúdico à opressão do rendimento. Porto Alegre: EST/ ESEF-UFRGS, 1994.

"O rendimento não é um fenômeno que possa ser isolado de um contexto maior onde encontra suporte a apoio. 
$\mathrm{O}$ rendimento encontra suas raízes filosóficas e ideológicas na própria dinâmica interna das ciências e da técnica; ele faz parte da imensa paisagem construída pelos homens da sociedade industrial. Portanto, o esporte de rendimento não pode ser entendido apenas como uma ação esportiva, mas como uma manifestação total da criatividade humana e, mais, em todas as suas implicações culturais possíveis"(p.35)

"O que se deve levar em consideração não é o rendimento, mas o valor simbólico que a ele é atribuído pelas diferentes culturas" (p.41)

"(••) é bom lembrar que toda a ação humana não elimina em nenhum momento a perspectiva de rendimento. O que deve ser observado é o significado ou a valor que ele adquire no desenvolver a atividade" (p.52).

Becker, P. ; Jung, P.; Wesp, H. e Wicklaus, J.M. Egalisiert und maximiert. In: Bekcer, P. (Hrgs.) Sport und Höchstleistung. Hamburg: Rowohlt, 1987. (Tradução: Valter Bracht).

"Com o esporte de rendimento vinculam-se concepções de tipos ideais de uma sociedade do rendimento na forma de jogo - seja isto entendido numa perspectiva positiva ou crítica. $\mathrm{O}$ esporte de rendimento condensa uma das categorias centrais para a explicação de nossa sociedade, $o$ prinicípio do rendimento. Esta categoria que orienta a vida em todos os setores sociais, forne- ce sentido principalmente para aquelas situações nas quais, por princípio, independentemente de idade, sexo, da origem étnica ou social, bens escassos devem ser distribuídos entre os participantes somente em função do seu rendimento individual. A orientação no rendimento e no seu aumento permanente, determina no campo do esporte o que é reconhecido e desejado em termos de corpo e movimento. $\mathrm{O}$ esporte de alto rendimento representa a importância que o rendimento possui para a sociedade moderna e age ao mesmo tempo como espelho, cuja dupla função consiste, por um lado, dar destaque, hipertrofiando num modelo 'simplificado', ao complexo societal na sua essência, e por outro, permite focar problemas específicos. A partir do esporte de rendimento é possível demonstrar de forma exemplar as précondições, a relevância e os efeitos de uma das mais importantes características explicativas da sociedade" (p. 186)

Larécio. Seção de humor da Revista Corpo e Movimento, APEF (SP), 1984, n.3, p.38.

Inusitado diálogo...

- Os jogos escolares servem para a fraternidade! Para a socialização dos participantes! Para a prática salutar das atividades gimnodesportivas! Para a Educação, enfim...

- Seu Diretor, a sua escola participa dos Jogos Escolares?
- Claro! Somos uma instituição educacional.

- E quais foram os resultados educacionais da participação do seu colégio?

- Duas medalhas de ouro, cinco de prata, três ter ceiros lugares, e o nosso time de basquete tava massacran do o inimigo quando foi des classificado por um juiz la drão.

$-\mathrm{Ah} ! ! !$

Vago, Tarcísio Mauro. O "esporte na escola" e o "esporte da escola": da negação radical para uma relação de tensão permanente. Revista Movimento, Vol. III, $\mathrm{n}^{\circ}$ 5, 1996/2, p.4-17.

"Assim, diferentemente de uma negação radical do 'esporte da escola' pelo 'esporte na escola', considero ser frutífero para a Educação Física avançar no sentido de construir uma relação de tensão permanente entre eles. Uma relação de tensão permanente que se estabeleça entre uma prática de esporte produzida e acumulada historicamente e uma prática escolar de esporte (a cultura escolar de esporte)" (p. 10)

"Afirma-se e defendese aqui, portanto, a escola como um lugar de produção de cultura. Cabe-lhe, então, ao tratar do esporte, produzir outras possibilidades de se apropriar dele - é o processo de escolarização do esporte $-\mathrm{e}$, com isso, influenciar a sociedade para conhecer e 
usufruir de outras possibilidades de se apropriar do esporte. Buscar uma tensão permanente entre o espaço social da escola e o espaço social mais amplo. É isso que caracteriza um movimento propositivo da escola em suas relações com outras práticas culturais da sociedade"(p.12)

"Não se trata, então, de agir apenas para que a escola tenha o 'seu' esporte. Trata-se de problematizar a prática cultural do esporte da sociedade (que é ao mesmo tempo, o esporte da e na escola), para reinventá-lo, recriá-lo, reconstruí-lo, e, ainda mais, produzi-lo a partir do específico da escola, para tencionar com aqueles já citados, que a sociedade incorporou a ele (e para superá-los). Não sendo mesmo possível à escola isolar-se da sociedade, já que a escola é, ela mesma, uma instituição da sociedade, uma de suas tarefas, então, é a de debater o esporte, de criticá-lo, de produzi-lo ... e de práticá-lo! Ora, se se quer o confronto - a tensão permanente - com os códigos e valores agregados ao esporte pela forma capitalista de organização social para construirmos outros valores a partir da escola (a solidariedade esportiva, a participação, o respeito à diferença, o lúdico, por exemplo), é fundamental que o façamos para toda a sociedade", (p. 13)

Bracht, Valter. Marcelinho Carioca, FHC e as regras do jogo. (texto inédito, impresso), 1999.

Há algum tempo atrás, um economista escrevendo no Jornal a Folha de São Paulo, estabelecia uma interessante analogia entre o que se vive no esporte internacional e na economia globalizada. Citando trechos de uma entrevista do tenista Peter Sampras, o autor argumentava que assim como no tênis, como dizia Sampras, também na economia globalizada os competidores precisam estar cada vez melhor preparados, pois a cada dia torna-se mais difícil manter-se competitivo. Sugeria o autor que deveríamos extrair lições, enquanto país, para nosso comportamento econômico.

Suspeitamos haver outras possibilidades de aproximar comportamentos do plano esportivo com outros de diferentes esferas sociais, como forma, não só de sugerir ações, mas, principalmente, como forma alternativa de entender a vida social.

Muito já se escreveu sobre a relação entre o esporte e a sociedade. $\mathrm{O}$ esporte, em muitas análises, é considerado a sociedade em um seu exemplo, em alguns casos, radicalizando, uma fotografia ou um reflexo da estrutura e valores sociais. Por outro lado, também é entendido como um modelo ideal (contra-fático) que antecipa o que seria uma sociedade igualitária e eminentemente meritocrática - o sucesso é exatamente proporcional ao rencimento alcançado, sendo este rendimento produzido sob regras iguais para todos e em relações de concorrência. Sem expressar opinião definitiva sobre esta relação, é possível relacionar alguns lances ou ocorrências do plano político com lances como o que envolveu o jogador Marcelinho Carioca em jogo recente.

No dia 11/02/98 enfrentaram-se em Aracaju, pela Copa do Brasil, o Cornthians Paulista e o Itabaiana de Sergipe. O primeiro tempo terminou com o placar de $1 \mathrm{x}$ 0 a favor do Corinthians, com um gol marcado por Marcelinho Carioca numa cobrança de falta, cuja existência, aliás, era questionada pelo locutor televisivo. No intervalo o Repórter da TV aproximouse de Marcelinho e perguntou o que ele havia achado do primeiro tempo do jogo. Resposta de Marcelinho: com a força de Jesus o Corinthians jogou bem e saiu vencedor do primeiro tempo (estou citando de memória). O repórter perguntou então sobre a falta; se ela havia realmente acontecido. Resposta do "crente" jogador: pra bater falta é preciso "cavar"uma falta!!! É preciso também ser inteligente!!! Risos de todos.

No mesmo dia do aludido evento esportivo o Presidente da República reuniase com o Sr. Paulo Maluf para "negociar" votos do PPB para a reforma da Previdência (Folha de São Paulo de 13/02/98, p.I.11). Maluf, aliás, é conhecido como um político capaz de realizar "jogadas inteligentes" — é detentor de uma "esperteza" tomada por uma parcela significativa da população como um valor positivo. Lances como este, para permanecer no linguajar esporti- 
vo, de Marcelinho(s) e de $\mathrm{FHC}(\mathrm{s})$ não ferem as regras formas do jogo (esportivo ou político). Um parênteses: nosso interesse aqui não é ressaltar a contradição entre a evocação de Jesus e o cinismo a la "Lei de Gérson" presente na atitude/fala do jogador, muito menos os, cada vez mais freqüentes, apelos ao divino do nosso Presidente da República. Nossa atenção recai sobre uma das características mais vinculadas à vida democrática, que é o respeito às regras.

$\mathrm{O}$ presidente $\mathrm{FHC}$ não infringe as regras formas do jogo quando negocia os votos para aprovar a reforma da previdência ou quando edita medidas provisórias - embora, da a sua performance recordista, levante a forte suspeita de que haja aí inconstitucionalidade, mas... quem julga? Aliás, em relação à regulamentação das medidas provisórias, Sandra Starling na Folha de São Paulo de 13/02/ 98 , p. I.3, mostra como a atitude/ação do Presidente é oportunista e esperta - sem que seja necessário desrespeitar as regras formais. Mas, o que poderíamos obstar se estes "jogadores" todos produzem este espetáculo atendo-se as suas regras constitutivas?

Também muito se escreveu sobre as limitações ou imperfeições da democracia representativa. A esquerda não cansa de apontá-las e a direita de justificá-las, não raramente com pitadas de cinismo explícito. A direita liberal fala inclusive de uma imperfeição natural e inevitável que, de tanto ser alardeada, acaba assumida pela população, provocando uma atitude de indignação conformista. Indignação que muitas vezes é metamorfoseada para uma espécie de auto-zombaria; fazemos piada de nós mesmos, de nossas mazelas anti-democráticas. Estas imperfeições, faz-se crer, são inevitáveis, são próprias do jogo, assim como inevitável é a globalização impostas pelas leis do mercado (com certeza, este o Deus de quem tanto se fala). Frente ao inevitável é inútil reagir.

Mas voltemos à analogia e à questão da regras do jogo. É senso-comum o entendimento de que liberdade democrática não significa viver na ausência de regras, mas, escolher (democraticamente) sob quais regras vamos conviver. Parece-nos que o conceito de auto-referencialidade (desenvolvido por H. Maturana na biologia e utilizado por N. Luhmann na sociologia) cabe bem à democracia. Não se chega à democracia como um ponto final, ela se constrói, e só se constrói democracia democraticamente, ou como escreveu F.Weffort, a luta entre as diferentes concepções de democracia precisa acontecer no plano da própria democracia. Assim, a construção e o respeito às regras assume fundamental importância no debate em torno da democracia.

O filósofo alemão K.O. Apel (em Diskurs und Verantwortung, 1987), enfrentando a questão da eticidade das regras esportivas, lembra, baseando-se em J. Searle, que existem dois tipos de regras: as constitutivas, que fazem, por exemplo, do futebol o futebol e as regras regulativas que estão implícitas, por exemplo, no fair play como norma das interações humanas. Estas segundas, dizem respeito, portanto, a normas seguidas ao nos movermos no interior das regras constitutivas. Eu posso afrontar o fair play, mesmo não infringindo as regras constitutivas de um esporte. Assim, para o autor, o problema ético ainda não está colocado quando nos limitamos à questão da observância ou não das regras do jogo. A questão ética se coloca no âmbito do "como" respeitamos as regras. Exemplifiquemos com o esporte. Relevante eticamente, aquilo que afeta a noção de justiça, não foi o fato de Marcelinho afrontar as regras constitutivas do futebol; isso ele não o fez. Relevante eticamente, é o fato de buscar vantagem no jogo simulando uma violação. No caso famoso da "mão santa" de Maradona na Copa do Mundo de Futebol de 1986, pelo fato dele esconder que havia cometido uma violação. E neste plano que devemos discutir sobre a moralidade ou não das ações. Oferecer cargos em troca de votos a favor da reforma da previdência, divulgar dados que interessam e omitir os que não interessam (Lei de Ricupero), por um lado, e por outro "cavar" uma falta (Lei de Marcelinho) ou dar um passo para fora da área para enganar o árbitro - 
como fez Nilton Santos em caso famos e alardeado como exemplo de esperteza do jogador brasileiro — situam-se no mesmo plano sob a perspectiva ética. Portanto, não basta para a construção da democracia respeitar as regras constitutivas do jogo, e preciso observá-las a partir de princípios éticos, como por exemplo o fair play, que claro é tanto desrespeitado por Marcelinho quanto por FHC.

Mas, nestes tempos pósmodernos e de globalização, tentar estabelecer pontos de referência éticos soa sempre como retrógrado, ultrapassado, tem cheiro de mofo iluminista. O que conta é o imediatismo pragmático; o que conta é o que aparenta ser e não o que é, mesmo porque não se admite mais a possibilidade de diferenciar a versão da realidade ou decidir sobre a verdade da versão. A disputa é pela imposição da versão, daí a necessidade de manter o controle, via aliciamento político-financeiro, dos meios de propagação das versões. A versão dominante não o é pelo seu conteúdo de verdade, mas pela sua capacidade de sedução - a espe-tacularização (esportivização) da política segue este princípio. Os atores, sejam políticos ou jogadores ou jogadores políticos, atuam na cena social sob a égide da espeta-cularização ou teatralização dos acontecimentos, onde ficção e realidade se confundem. Produz-se uma hiper-realida-de que só é rompida com extrema dificuldade. É rompida momentaneamente nas filas dos hospitais, na carta de demissão do emprego. Seus impactos, no entanto, são absorvidos via ressemantização/ ressignificação a partir do código da inevitabilidade da globalização econômica e das leis de mercado: privatização dos serviços de saúde por um lado, e por outro, flexibilização dos contratos de trabalho - melhor um emprego virtual do que nenhum.

Marcelinho e FHC, no esporte e na política, escolheram jogar o jogo respeitando as regras (constitutivas). Mas como eles se movem no interior do quadro balizado por estas regras, a forma como eles as respeitam é questionável eticamente. No entanto, isto parece provocar mais a aquiescência de boa parte dos espectadores do que uma indignação mobiliza-dora, talvez porque não se infrinja frontalmente as regras, apenas o fair play implícito, que digase de passagem, não fez escola nem na política nem no esporte. Aliás, existem boas chances do esporte moderno e da sociedade capitalista serem incompatíveis com o fair-play. Neste sentido o esporte e a política reforçam os seus times reciprocamente, sendo que a derrota é da democracia e consequentemente da maioria da população brasileira.

\section{NOTAS}

${ }^{l} A$ adjetivação do esporte como de rendimento solicita por si só uma discussão aprofundada, o que tomaria todo o espaço aqui disponível. Assim, apenas o- bservo que o rendimento está presente em maior ou menor grau em toda prática esportiva, no entanto, numa determinada manifestação esportiva o rendimento é elevado à categoria central, ao elemento definidor e organizador das ações. É a este esporte que estaremos chamando de esporte de rendimento.

${ }^{2}$ Já que foi no interior ou a partir das Escolas de Educação Física, Departamentos e Centros de Educação Física das Universidades que no Brasil desenvolveu-se uma vertente que faz críticas contundentes à função social do esporte. Ou seja, é no âmbito acadêmico da EF que existem resistências ao fenômeno esportivo na forma como ele se apresenta em nossa sociedade.

${ }^{3}$ Em relação às análises críticas do fenômeno esportivo remetemos o leitor a uma vasta literatura que compreende entre outros: Brohm (1978); Hargreaves (1982); Kunz (1994) e Bracht (1997).

${ }^{4}$ Não ignoro outras e anteriores reações críticas ao esporte presentes na história da EF, no entanto, elas apresentam caráter esporádico. Um movimento mais sistemático e de alguma repercussão parece mesmo só ter acontecido a partir da década de 80 .

5 A prática esportiva com sentido diferente daquele predominante no esporte de rendimento já está presente no âmbito da cultura. Trata-se, portanto, de tematizar também estas práticas esportivas, que na maiorira das vezes são marginais no âmbito do sistema esportivo, ou quando rivalizam com o sentido oficial, tendem a ser incorporadas e resignificadas.

${ }^{6}$ Observe-se que não sou contra as classificações pura e simplesmente. Elas têm função didática importante, na medida em que simplificam, organizam a realidade de uma determinada forma de maneira a torná-la intelegível. O problema está em como se trabalha com elas, com os conceitos na forma de tipos 
ideais. O que estamos observando na EF é um uso abusivo e equivocado das classificações, principalmente, das ditas tendências pedagógicas. A simplificação das classificações é novamente simplificada, gerando um simplismo e maniqueísmo extremamente prejudiciais.
7Esta perspectiva de crítica ao esporte de rendimento Eichberg (1979) denomina de "cristã-conservadora".

${ }^{8}$ Desenvolvi este tema em Bracht (1996).

${ }^{9}$ Estou entendendo por Pedagogia Crítica uma vertente da pedagogia que tem como pers- pectiva a transformação da sociedade capitalista. Ver a respeito: Saviani (1983) e Silva (1999).

*Valter Bracht é professor de Educação Física do Departamento de Ginástica do Centro de Educação Física e Desportos da Universidade Federal do Espírito Santo. 